원 저

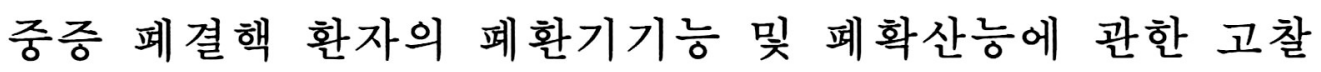

부산대학교 의과대학 내과학교실

(지도 : 신 영 기 교수)

김 호 균 - 박 장 근

$=$ Abstract $=$

\title{
Ventilatory Function and Diffusion Capacity of the Lung in Patients with Far Advanced Pulmonary Tuberculosis
}

\author{
Ho Kyun Kim, M.D. and Jang Geun Park, M.D. \\ Department of Internal Medicine, College of Medicine, Pusan National University \\ (Director: Proffessor Young Kee Shin, M.D.)
}

The authors studied the ventilatory function and diffusion capacity of the lung in patients with far advanced pulmonary tuberculosis from January 1985 to August 1986. The studied subjects were consisted of 80 patients with far advanced pulmonary tuberculosis and comparable with 120 nonsmoking healthy persons as a control.

The results obtained were summerized as follows:

1) The parameters derived from forced expiratory volume curve in patients with far advanced pulmonary tuberculosis, $\mathrm{FVC}, \mathrm{FEV}_{1}, \mathrm{FEV}_{1} \%, \mathrm{FEF} 25 \sim 75 \%$ and $\mathrm{FEF} 75 \sim 85 \%$, were significantly lower than those of normal control $(\mathrm{p}<0.05)$.

2) The parameters derived from maximal expiratory flow volume curve, PEFR, $\dot{\mathrm{V}} \max 25 \%, \dot{\mathrm{V}} \max$ $75 \%$, were significantly lower than those of normal control $(\mathrm{p}<0.05)$.

3) The parameters derived from forced expiratory volume curve and maximal expiratory flow volume curve in patients with far advanced pulmonary tuberculosis trended to decrease as duration of illness was increased.

4) The parameters of volume-adjusted forced expiratory volume curve and maximal expiratory flow volume curve in patients with far advanced pulmonary tuberculosis trended to decrease as duration of illness was increased.

5) DLco and DLco/ $\dot{\mathrm{V} A}$ in patients with far advanced pulmonary tuberculosis were significantly lower than those of normal control $(\mathrm{p}<0.05)$.

6) In patients with far advanced pulmonary tuberculosis, the lung diffusion capacity was directly related to FVC and FEV ${ }_{1}(r=0.578, p<0.001$ and $r=0.457, p<0.05)$.

7) The $\mathrm{PaO}_{2}$ and arterial $\mathrm{O}_{2}$ saturation in patients with far advanced pulmonary tuberculosis were significantly decreased than those of normal control $(\mathrm{p}<0.001$ and $\mathrm{p}<0.01)$ but $\mathrm{PaCO}_{2}$ in patients with far advanced pulmonary tuberculosis was not different as compared with control.

서 론

대부분의 선진국에서는 1940 년대 이후 다수의 우수한

본 논문의 요지는 제 63 차 대한결핵학희 추계학술대회석상 에서 발표되었음.
항결핵제의 개발과 더불어 효과적인 결핵관리사업으로 결핵의 유병율이나 결핵으로 인한 사망이 급격히 감소되 어 왔으며, 근래에는 연령별로도 폐결핵은 젊은 연령층 에서 보다는 65 세 이상의 노년층에서 가장 흔히 발견되 는 질환으로 바뀌었다 ${ }^{1 \sim 4)}$. 그러나 우리나라에서는 1965 년에 $5.1 \%$ 이던 결핵 유병율이 1985 년에는 $2.2 \%$ 로 감 
소는 하였으나 아직까지도 활동성 폐결핵 환자가 약 100 만명으로 추산되고 있는 바호, 이 질환에 대한 다각적인 관심과 퇴치를 위한 보다 적극적인 대책이 요구된다 하 겠다.

폐기능검사는 결핵의 확진과는 관계가 없으며 폐결핵 의 수술적치료는 적응이 줄어든 지금에와서는 그 필요성 이 적어졌다고는 하나, 여러가지 원인으로 인하여 결핵 감염이 장기간 지속됨으로해서 폐조직의 파괴가 심한예 특히 중증 폐결핵 환자에서는 페기능검사를 통하여 차후 사회생할에 적응할 수 있는 범위를 결정해 주는 척도로 삼을 수 있다는 점에서 그 의의가 있다. 또한 호흡 부전 증으로 발전할 가능성에 대한 예견이나, 호흡곤란의 호 전 또는 악화정도를 파악하기 위한 지표 및 기도에 발생 하는 타질환과의 감별을 위하여 필요한 검사라 할 수 있 다 ${ }^{6)}$.

저자들은 각종 폐질환의 호흡기능 이상을 추구하기 위 한 연구의 일환으로 1985년부터 1986년까지 부산대학교 의과대학 부속병원 결핵격리병동에 중증 폐결핵으로 진 단되어 입원치료 하였던 환자를 대상으로 폐기능 검사를 실시하여 훙미있는 결과를 얻었기에 문헌고찰과 함께 보 고하는 바이다.
이 없으며, 최소한 최근 1 년간 급성 폐감염의 병력이 없 고, 호흡기 증상이 없으며, 이학적 검사상 정상이며 비 홉연 건강성인 120 예 (남여 각각 60 예) 로 하였다. 관찰군 과 대조군의 연령 및 신체조건은 Table 1에서 보는 바 와 같다.

중증 폐결핵 환자에서 유병기간을 임으로 나누어 보면 총 80 예중 5 년까지 (A군) 가 35 예 $(48.8 \%), 6$ 년부터 10 년 사이(B군)가 19 예(23.7\%), 10 년이상(C군)이 26예 (32.5\%)였다 (Table 2).

만성 중증 폐결핵의 진단은 과거병력, 홍부 $\mathrm{X}$-선검사, 객담도말검사 및 결핵균 배양검사 등을 종합하여 판정하 였다.

\section{2. 방 법}

노력성 호기폐활량곡선 (forced expiratory volume curve, $\mathrm{FEV}$ ), 최대호기 류 량-용적 곡 선 (maximal expiratory flow-volume curve, MEFV) 및 폐확산능 검사는 Gould(미국)제품인 SRL 1,000 IV Computerized Pulmonary Function Laboratory를 사용하였으 며, 피검자는 식후 약 2 시간이 지난뒤 충분한 휴식을 시

Table 1. Physical Status of Case Materials

\begin{tabular}{|c|c|c|c|c|}
\hline & \multicolumn{2}{|c|}{ Male } & \multicolumn{2}{|c|}{ Female } \\
\hline & $\begin{array}{c}\text { Control } \\
\text { ( } 60 \text { cases) }\end{array}$ & $\begin{array}{c}\text { FA TB } \\
\text { ( } 46 \text { cases) }\end{array}$ & $\begin{array}{c}\text { Control } \\
\text { ( } 60 \text { cases) }\end{array}$ & $\begin{array}{l}\text { FA TB } \\
\text { ( } 34 \text { cases) }\end{array}$ \\
\hline Age ( year) & $41.40 \pm 11.23$ & $39.48 \pm 15.48$ & $43.52 \pm 14.62$ & $37.83 \pm 13.33$ \\
\hline Height $(\mathrm{cm})$ & $168.89 \pm 4.76$ & $170.52 \pm 5.61$ & $155.42 \pm 5.81$ & $157.59 \pm 4.99$ \\
\hline Weight ( kg) & $61.29 \pm 8.96$ & $54.91 \pm 7.67$ & $52.28 \pm 8.61$ & $47.97 \pm 8.42$ \\
\hline $\operatorname{BSA}\left(\mathrm{m}^{2}\right)$ & $1.7 \pm 0.12$ & $1.64 \pm 0.12$ & $1.50 \pm 0.12$ & $1.47 \pm 0.11$ \\
\hline
\end{tabular}

FA TB : Far advanced tuberculosis

BSA : Body surface area

Values are expressed as mean $\pm \mathrm{SD}$

\section{대상 및 방법}

1. 대 상

1985년 1월부터 1986년 8월까지 만성 중증 폐결핵으 로 진단되어 부산대학교 의과대학 부속병원 결핵격리 병 동에 입원 치료 하였던 80 예 (남자 46예 및 여자 34예)를 관찰대상으로 하였고, 대조군으로는 심폐질환의 과거력
Table 2. Duration of Illness in Patients with Far Advanced Pulmonary Tuberculosis

\begin{tabular}{|c|c|c|}
\hline Duration (year) & No. of cases & $(\%)$ \\
\hline-5 (group A) & 35 & (43.8) \\
\hline $6-10($ group $B)$ & 19 & (23.7) \\
\hline $10-\quad($ group $C)$ & 26 & (32.5) \\
\hline Total & 80 & $(100.0)$ \\
\hline
\end{tabular}


킨후, 검사방법을 자세히 설명하고 좌위에서 실시하였 다.

$\mathrm{FEV}$ 곡선의 검사방법은 실내공기를 전폐용량(TLC) 수준까지 흡입시킨 다음 최대한으로 빨리 잔기량 $(\mathrm{RV})$ 수 준까지 완전히 호출시키는 동안 호기시간은 $\mathrm{X}$ 축에 호기 량은 $\mathrm{Y}$ 축에 기록하여 노력성 폐활량 $(\mathrm{FVC})$, 노력성 호 기폐 활량 1 초치 $\left(\mathrm{FEV}_{1}\right)$ 및 그 비율 $\left(\mathrm{FEV}_{1} \%\right)$, 최대중간 호기류 속도(FEF 25 75\%) 및 $\mathrm{FVC}$ 의 $75 \sim 85 \%$ 를 호 출할때의 기류속도(FEF 75 85\%)를 측정하였다.

$\mathrm{MEFV}$ 곡선도 위와 같은 방법으로 동시에 검사하면 서 호기량은 $\mathrm{X}$ 축에, 기류속도는 $\mathrm{Y}$ 축에 기록하면서 최 대호기류속도(peak expiratory flow rate, PEFR), 노 력성 호기폐활량의 $25 \%, 50 \%, 75 \%$ 를 호기할때의 기 류속도 즉 $\dot{\mathrm{V}} \max 25 \%, \dot{\mathrm{V}} \max 50 \%, \dot{\mathrm{V}} \max 75 \%$ 를 측 정하였다.

폐확산능은 피검자를 완전 호기시킨 상태에서 혼합표 준가스 $\left(\mathrm{CO}_{2} 0.3 \%, \mathrm{He} 10 \%, \mathrm{O}_{2} 21 \%, \mathrm{~N}_{2}\right.$ balance $)$ 를 전폐용량까지 흡입시킨 후 10 초간 호흡을 정지시킨 다음 한꺼번에 호출시키면 호기가스는 표본축출 bag에 모아 지며 이 bag내로 들어간 폐포내 가스의 $\mathrm{He}$ 과 $\mathrm{CO}$ 농도 가 분석되어 폐확산능이 자동측정된다.

동맥혈내 분석은 Corning사(미국)의 Corning 175동
맥혈 가스분석기를 이용하였으며, 최소한 30 분이상 산소 흡입을 시키지않는 상태에서 heparin으로 처리한 주사 기로 동맥혈을 채취하여 즉시 검사하였다.

폐기능의 계측은 3 회이상 반복 시행하여 최대치를 나 타내는 곡선을 택하여 분석하였고, 본 관찰에서 사용된 추정정상치는 SRL $1000 \mathrm{IV}$ Computerized Pulmonary Function Laboratory에 기억된 Goldmann, Morris, Koly등이 제안한 공식기을 이용하였다. 각군간의 계측치 의 차이에 대하여는 통계학적으로 그 유의성을 검정하였 다.

\section{성 적}

정상 대조군과 중증 폐결핵 환자에서 $\mathrm{FEV}$ 곡선검사 를 실시하여 구한 계측치들을 비교하면 $\mathrm{FVC}, \mathrm{FEV}_{1}$, $\mathrm{FEV}_{1} \%, \mathrm{FEF} 25 \sim 75 \%, \mathrm{FEF} 75 \sim 85 \%$ 모두 정상대 조군에 비하여 환자군이 유의하게 감소되어 있음을 인정 할 수 있었다(Table 3).

정상대조군과 중증 폐결핵 환자에서 $\mathrm{MEFV}$ 곡선검사 를 실시하여 구한 각 계측치들을 비교하면 PEFR, $\dot{\mathrm{V}} \max$ $25 \%, \dot{\mathrm{V}} \max 50 \%, \dot{\mathrm{V}} \max 75 \%$ 모두 정상대조군에 비 하여 환자군에서 유의하게 감소되어 있었다(Table 4).

Table 3. Comparison of Parameters Derived from Forced Expiratory Volume Curve Between Control and Patients with Far Advanced Pulmonary Tuberculosis

\begin{tabular}{lccc}
\hline \hline & Control (120 cases) & FA TB $(80$ cases $)$ & P value \\
\hline FVC & $92.71 \pm 18.08$ & $69.56 \pm 29.73$ & 0.05 \\
FEV $_{1}$ & $93.45 \pm 26.17$ & $66.24 \pm 31.57$ & 0.05 \\
FEV $_{1} \%$ & $89.84 \pm 12.54$ & $66.56 \pm 14.68$ & 0.05 \\
FEF 25 - 75 & $94.27 \pm 22.74$ & $62.66 \pm 27.60$ & 0.05 \\
FEF 75-85 & $105.43 \pm 28.46$ & $62.52 \pm 23.62$ & 0.05 \\
\hline
\end{tabular}

Values are expressed as percentages of the predicted normal values

Table 4. Comparison of Parameters Derived from Maximal Expiratory Flow-volume Curve Between Control and Patients with Far Advanced Pulmonary Tuberculosis

\begin{tabular}{lccc}
\hline \hline & Control (120 cases) & FA TB (80 cases) & P value \\
\hline PEFR & $91.66 \pm 19.25$ & $74.85 \pm 25.73$ & 0.05 \\
$\dot{V} \max 25$ & $86.48 \pm 27.86$ & $67.63 \pm 17.34$ & 0.05 \\
$\dot{V} \max 50$ & $97.91 \pm 26.63$ & $71.18 \pm 16,88$ & 0.05 \\
$\dot{V} \max 75$ & $102.84 \pm 19.54$ & $74.60 \pm 15.73$ & 0.05 \\
\hline
\end{tabular}

PEFR : Peak expiratory flow rate

Values are expressed as percentages of the predicted normal values 
중증 폐결핵 환자의 $\mathrm{FEV}$ 곡선검사에서 구한 각 계측 치를 유병기간에 따라 비교하면, $\mathrm{A}$ 군과 $\mathrm{B}$ 군사이에는 $\mathrm{FVC}$ 가 $\mathrm{B}$ 군과 $\mathrm{C}$ 군사이에는 $\mathrm{FVC}$ 와 $\mathrm{FEV}_{1}$ 에서 유의한 차이가 있었고 $\mathrm{A}$ 군과 $\mathrm{C}$ 군사이에는 $\mathrm{FVC}, \mathrm{FEV}_{1}, \mathrm{FEV}$ ${ }_{1} \%, \mathrm{FEF} 25 \sim 75 \%, \mathrm{FEF} 75 \sim 85 \%$ 모두 유의한 차이가 있었다(Table 5).

중증 폐결핵 환자의 $\mathrm{MEFV}$ 곡선검사에서 구한 각 계측 치를 유병기간에 따라 비교하면, $\mathrm{A}$ 군과 $\mathrm{B}$ 군사이에는 $\dot{\mathrm{V}} \max 50 \%$ 와 $\dot{\mathrm{V}} \max 75 \%$ 에서 유의한 차이가 있었고 $\mathrm{B}$ 군과 $\mathrm{C}$ 군 그리고 $\mathrm{A}$ 군과 $\mathrm{C}$ 군사이에서는 $\mathrm{PEFR}, \dot{\mathrm{V}} \max$
$25 \%, \dot{\mathrm{V}} \max 50 \%, \dot{\mathrm{V}} \max 75 \%$ 모두 유의한 차이를 관 찰할 수 있었다 (Table 6).

중등 폐결핵환자의 $\mathrm{MEFV}$ 곡선검사에서 구한 각 계 측치를 FVC로 교정한 용량교정치 (volume-adjusted value) 의 성적을 유병기간에 따라 비교하면, $\mathrm{A}$ 군과 $\mathrm{B}$ 군 사이에는 유의한 차이가 없었으나, $\mathrm{B}$ 군과 $\mathrm{C}$ 군 그리 고 $\mathrm{A}$ 군과 $\mathrm{C}$ 군 사이에는 유의한 차이를 인정할 수 있었 다(Table 7).

정상대조군과 중증 폐결핵 환자의 폐확산능 $(\mathrm{DLco})$ 및 폐용적에 대한 폐확산능 $(\mathrm{DLco} / \mathrm{VA})$ 을 비교하면, 양자

Table 5. Comparison of Parameters Derived from Forced Expiratory Volume Curve by the Duration of Illness in Patients with Far Advanced Pulmonary Tuberculosis

\begin{tabular}{llccrrr}
\hline \hline & $\begin{array}{c}5 \text { years } \\
(\mathrm{A}: \mathrm{n}=35)\end{array}$ & $\begin{array}{c}6-10 \text { years } \\
(\mathrm{B}: \mathrm{n}=19)\end{array}$ & $\begin{array}{c}>10 \text { years } \\
(\mathrm{C}: \mathrm{n}=26)\end{array}$ & $\mathrm{A}-\mathrm{B}$ & $\begin{array}{c}\text { P value } \\
\mathrm{B}-\mathrm{C}\end{array}$ & $\mathrm{A}-\mathrm{C}$ \\
\hline FVC & $90.11 \pm 22.94$ & $71.74 \pm 18.86$ & $58.54 \pm 11.58$ & 0.05 & 0.05 & 0.05 \\
FEV1 & $83.63 \pm 30.92$ & $77.16 \pm 24.40$ & $58.47 \pm 13.01$ & NS & 0.05 & 0.05 \\
FEV1\% & $74.29 \pm 14.15$ & $58.47 \pm 15.26$ & $61.16 \pm 14.99$ & NS & NS & 0.05 \\
FEF 25 - 75 & $72.65 \pm 27.60$ & $69.88 \pm 26.41$ & $56.81 \pm 16.32$ & NS & NS & 0.05 \\
FEF 75 - 85 & $74.53 \pm 43.62$ & $65.67 \pm 29.32$ & $51.58 \pm 22.65$ & NS & NS & 0.05 \\
\hline
\end{tabular}

Values are expressed as percentages of the predicted normal values

NS : Not significant

Table 6. Comparison of Parameters Derived from Maximal Expiratory Flow-volume Curve by the Duration of Illness in Patients with Far Advanced Pulmonary Tuberculosis

\begin{tabular}{lcccrcc}
\hline \hline & $\begin{array}{c}\text { < years } \\
(\mathrm{A}: \mathrm{n}=35)\end{array}$ & $\begin{array}{c}6-10 \text { years } \\
(\mathrm{B}: \mathrm{n}=19)\end{array}$ & $\begin{array}{c}>10 \text { years } \\
(\mathrm{C}: \mathrm{n}=26)\end{array}$ & A-B & $\begin{array}{l}\text { P value } \\
\text { B-C }\end{array}$ & A-C \\
\hline PEFR & $89.37 \pm 16.54$ & $83.93 \pm 26.67$ & $50.77 \pm 25.34$ & $\mathrm{NS}$ & 0.05 & 0.05 \\
$\dot{\mathrm{V}} \max 25$ & $86.32 \pm 25.39$ & $76.48 \pm 20.81$ & $62.54 \pm 20.39$ & $\mathrm{NS}$ & 0.05 & 0.05 \\
$\dot{\mathrm{V}} \max 50$ & $86.05 \pm 28.97$ & $70.39 \pm 26.64$ & $57.92 \pm 17.53$ & 0.05 & 0.05 & 0.05 \\
$\dot{\mathrm{V}} \max 75$ & $79.37 \pm 17.10$ & $56.85 \pm 21.41$ & $45.46 \pm 13.70$ & 0.05 & 0.05 & 0.05 \\
\hline
\end{tabular}

Values are expressed as percentages of the predicted normal values

NS : Not significant

Table 7. Comparison of Volume-adjusted Maximal Expiratory Flow-volume Curve by the Duration of Illness in Patients with Advanced Pulmonary Tuberculosis

\begin{tabular}{llccccc}
\hline \hline & $\begin{array}{c}<5 \text { years } \\
(\mathrm{A}: \mathrm{n}=35)\end{array}$ & $\begin{array}{c}6-10 \text { years } \\
(\mathrm{B}: \mathrm{n}=19)\end{array}$ & $\begin{array}{c}>10 \text { years } \\
(\mathrm{C}: \mathrm{n}=26)\end{array}$ & $\mathrm{A}-\mathrm{B}$ & $\begin{array}{r}\text { P value } \\
\text { B-C }\end{array}$ & A-C \\
\hline $\mathrm{FEFR} / \mathrm{FVC}$ & $2.02 \pm 0.67$ & $1.96 \pm 0.43$ & $1.61 \pm 0.25$ & $\mathrm{NS}$ & 0.05 & 0.05 \\
$\dot{\mathrm{V}} \max 25 / \mathrm{FVC}$ & $1.85 \pm 0.38$ & $1.90 \pm 0.51$ & $1.28 \pm 0.37$ & $\mathrm{NS}$ & 0.05 & 0.05 \\
$\dot{\mathrm{V}} \max 50 / \mathrm{FVC}$ & $0.95 \pm 0.41$ & $0.84 \pm 0.22$ & $0.61 \pm 0.33$ & $\mathrm{NS}$ & 0.05 & 0.05 \\
$\dot{\mathrm{V}} \max 75 / \mathrm{FVC}$ & $0.27 \pm 0.16$ & $0.24 \pm 0.13$ & $0.17 \pm 0.09$ & NS & 0.05 & 0.05 \\
\hline
\end{tabular}

NS : Not significant 
모두 정상대조군에 비하여 환자군에서 유의하게 감소되 어 있었다(Table 8).

중증 폐결핵 환자에서 폐확산능은 $\mathrm{FVC}$ 및 $\mathrm{FEV} 1$ 과 각 각 서로 유의한 상관관계를 보였다(Fig. 1 및 2).

Table 8. Comparison of Lung Diffusion Capacity Between Control and Patients with Far Advanced Pulmonary Tuberculosis

\begin{tabular}{lccc}
\hline & $\begin{array}{c}\text { Control } \\
(36 \text { cases })\end{array}$ & $\begin{array}{c}\text { FA TB } \\
(25 \text { cases })\end{array}$ & P value \\
\hline DLco & $94.31 \pm 6.20$ & $62.16 \pm 15.10$ & 0.05 \\
DLco/VA & $93.06 \pm 6.63$ & $63.68 \pm 13.66$ & 0.05 \\
\hline
\end{tabular}

Values are expressed as percentages of the predicted normal values

DLco : Lung diffusion capacity

DLco/VA : Lung diffusion capacity/alveolar ventilation

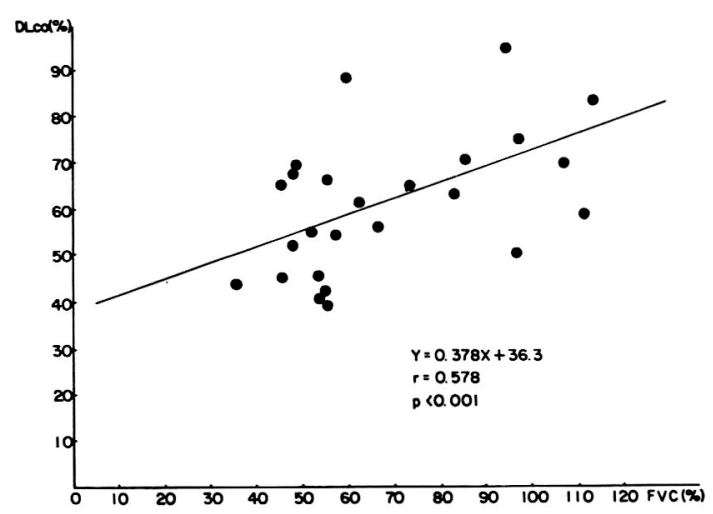

Fig. 1. Relation between DLco and FVC in patients with far advanced pulmonary tuberculosis.

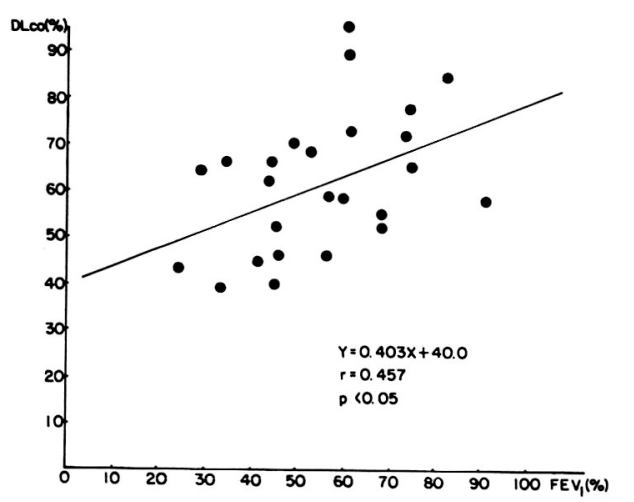

Fig. 2. Relation between DLco and $\mathrm{FEV}_{1}$ in patients with far advanced pulmonary tuberculosis.
정상대조군과 중증 폐결핵 환자에서 동맥혈 가스 분석 을 시행 하여 산소분압 $\left(\mathrm{PaO}_{2}\right)$, 이산화탄소분압 $\left(\mathrm{PaCo}_{2}\right)$ 및 산소포화도 $\left(\mathrm{SaO}_{2}\right)$ 을 비교하면 $\mathrm{PaCo}_{2}$ 을 제외하고는 $\mathrm{PaO}_{2}$ 및 $\mathrm{SaO}_{2}$ 는 정상대조군에 비하여 환자군에서 유의 하게 감소되어 있었다(Table 9).

Table 9. Comparison of Arterial Blood Gas Between Control and Patients with Far Advanced Pulmonary Tuberculosis

\begin{tabular}{lccc}
\hline \hline & $\begin{array}{c}\text { Control } \\
\text { (22 cases) }\end{array}$ & $\begin{array}{c}\text { FA TB } \\
(18 \text { cases })\end{array}$ & P value \\
\hline $\mathrm{PaCO}_{2}$ & $37.82 \pm 2.62$ & $40.83 \pm 7.16$ & N.S. \\
$\mathrm{PaO}_{2}$ & $90.71 \pm 7.94$ & $72.5 \pm 14.09$ & 0.001 \\
$\mathrm{SaO}_{2}$ & $97.04 \pm 0.95$ & $90.40 \pm 8.77$ & 0.1 \\
\hline
\end{tabular}

$\mathrm{SaO}_{2}$ : Arterial $\mathrm{O}_{2}$ saturation

N.S. : Not significant

\section{고 안}

폐결핵의 치료에 있어서 페적출술이 흔히 적용되었던 시대에는 수술적응여부를 판단하기 위한 수술전 평가로 서 폐기능검사가 필수적인 것이었으나 우수한 항결핵제 의 개발에 힘입어 외과적 치료의 필요성이 적어진 오늘 날에 와서는 폐결핵 환자에 대한 폐기능 검사의 중요성 이 상대적으로 적어진 것은 사실이다. 그러나 폐조직의 파괴가 심한 중증 폐결핵 환자에서는 폐기능 검사를 통 하여 병변의 범위와 주된 병소의 위치를 파악한다는 것 은 치료방침의 설정에 필요할 뿐만 아니라 치료후 사희 생활에의 적응도 및 호흡부전으로 진행 될 가능성에 대한 예견의 지표로 삼을 수 있으므로 홍부 X-선검사 및 객 담검사와 더불어 생리적 기능검사의 주기적인 실시는 매 우 중요한 의미를 가진달.

폐결핵 환자에서 폐기능 검사를 실시하였을 때 결핵 병 변의 범위가 좁은 예에서는 폐실질의 직접적인 손상에 의 한 기능이상이 나타난다기 보다는 늑막염, 무기폐, 폐섬 유화등 결핵의 합병증에 기인할 것으로 믿어지며, 장시 간의 유병기간을 가진 중증 폐결핵 환자에서는 폐실질의 파괴가 직접적으로 폐의 기능적 장애를 초래한다고 하며, 이때 나타날 수 있는 페기능 이상은 제 한성환기장애, 폐 실질의 섬유화에 의한 폐기종, 폐결핵에 동반된 기관지 염 및 대기도의 협착에 의한 폐색성 환기장애, 폐실질의 
파괴에 의한 폐조직의 손실, 폐동맥압의 증가 등으로 알 려져있다9,10). 이와같이 폐결핵 환자에서는 그 정도에 관 계없이 특징적으로 나타나는 폐기능 검사소견은 없고 비 특이적인 여러가지 이상소견이 관찰되며 ${ }^{11)}$. 이러한 요인 들의 단독 혹은 공존 여부에 따라 폐의 기능이상은 다양 하게 나타나므로 폐결핵에서의 폐기능 이상을 일률적으 로 표현하기는 쉽지않다 ${ }^{12)}$.

폐결핵의 병변범위가 넓어짐에 따라 가장 흔히 나타나 는 폐기능 이상소견은 제한성 환기장애이다. 제한성 환 기장애는 결핵의 합병증으로 발생되는 기훙이나 늑막염 또는 횡경막의 유착등 심한 섬유화가 그 원인이되며 폐 활량 및 전폐용량의 감소를 나타낸다. 대부분의 예에서 잔기량은 정상범위내에 있으므로 잔기량/전폐용량의 비 는 증가를 보이는 것이 보통인데 이는 주로 폐활량의 감 소에 기인한다 ${ }^{13,14)}$. 저자들의 관찰에서도 대조군과 비교 할때 중증 폐결핵 환자의 폐활량은 현저히 감소되어 있 음을 볼 수 있었고, 이는 유병 기간이 길어짐에 따라 더 욱 뚜렷이 감소하는 경향이 었다.

폐결핵 환자를 대상으로한 폐기능 검사상 정도의 차이 는 있었으나 약 반수 $(50.8 \%)$ 에서 폐색성 기도 이상 소 견을 관찰할 수 있었다는 보고가 있으며 ${ }^{15)}$, 이는 고령일 수록, 유병기간이 길수록, 질병의 범위가 넓을수록 더욱 심하였다고 하며, 폐결핵이 장기간 지속되면 폐기종의 원 인이 되는 것으로 추측된다고 하였다. 저자들의 예에서 도 대조군에 비하여 중증 폐결핵 환자에서는 호기류속도 의 뚜렷한 감소를 보이고 있으며 유병기간이 길어짐에 따 라 그 정도는 더욱 현저하였다. 그러나 $\mathrm{MEFV}$ 곡선에서 구한 계측치에는 비교적 심한 변이성이 예견되므로 ${ }^{16)}$, 이 를 배제하기 위하여 호기류 속도를 폐활량 또는 전페용 량으로 교정하여 표시해야 한다는 보고에 주목할 필요가 있다. 즉 호기류 속도의 실즉치는 용량의존성 (volumedependent)으로써 비교정치의 감소가 언제나 기도폐색 을 의미 할 수는 없으며, 폐용량이 감소된 예에서는 호 기류 속도의 용량교정치가 호기류 속도의 이상유무를 판 단하는데 더욱 적합한 지표가 된다는 이론이다 ${ }^{17}$. 저자 들의 관찰에서 폐활량으로 교정한 호기류 속도가 또한 유 병기간이 길어짐에 따라 현저히 감소함을 볼 수 있었던 바, 이는 중증 폐결핵인 경우 폐용량의 감소와는 별도로 기도 폐색이 나타나고 있음을 시사하는 소견으로 간주된 다.

만성적 경과를 취하는 폐결핵에서는 폐확산능도 장애
를 받고 있는 것으로 알려져 있는데 일산화탄소를 이용 한 폐확산능검사 결과는 홍부 X-선상의 병변의 정도와 매우 유의한 상관성을 가지며, 그 장애의 정도는 홍부 X선 소견에서 기대했던 것보다 대부분 더 심하게 나타난 다고 한다 ${ }^{18,19)}$. 그러나 폐확산능 장애의 정도와 결핵병 변의 범위와는 무관하다는 주장도 있다 ${ }^{20)}$. 또한 폐확산 능의 장애는 폐간질성 섬유화가 심하거나 폐기종이 공존 하는 경우에 더욱 현저히 나타난다.

폐결핵에 의한 제한성 및 폐색성 환기장애는 동맥혈내 산소분압의 감소, 이산화탄소분압의 증가 및 폐포-동맥 혈산소분압차 $\left(\mathrm{A}-\mathrm{aDO}_{2}\right)$ 의 증가를 초래한다. 또한 환기 분포의 불균형 및 폐용압율의 감소도 나타나며, 이러한 변화를 일으키는데 가장 중요한 역활을 할 것으로 판단 되는 인자는 질병의 범위와 유병기간이다 ${ }^{2124)}$. 저산소 증은 폐결핵의 초기에는 경한 정도의 이상소견을 보이거 나, 운동시만 나타나지만 병변이 광범위해지면 이는 폐 동맥압 증가의 유인이 되어 결국 폐심성으로 진행되는 바, 적절한 치료로 결핵이 치유된 수년후에도 이로 인하 여 사망하는 예가 적지 않음을 염두에 두어야 한다 ${ }^{25 ~ 26)}$. 그러나 중증 폐결핵환자에서 폐동맥 고혈압증이 발생하 는 이유에 대하여 저산소혈증보다는 폐혈관상 (vascular bed)의 파괴가 더욱 강조되기도 한다 ${ }^{11,27)}$.

중증폐결핵환자에서 방사선 동위원소를 이용한 폐주사 상 폐관류도 홍부 X-선 소견에서 기대했던 것보다 더욱 심한 감소를 보이는 데 이는 적절한 치료로 어느 정도 희 복이 가능한 것으로 믿어진다 ${ }^{28,29)}$. 환기관류 불균형은 만 성 폐결핵보다는 급성으로 발생하는 속립성결핵에서 더 빈번히 관찰되는 소견이다 ${ }^{10)}$. 본 관찰에서는 폐관류 검 사는 시행하지 못하였다.

중증 폐결핵 환자의 생리적 폐기능 변화의 해석에 있 어서 염두에 두어야 할 점은 폐결핵 자체 또는 결핵의 합 병증과는 무관하게 발생한 만성기관지염을 포함한 폐색 성 폐질환등이 공존하는 경우가 상당수 있다는 것이며 특 히 환자의 나이가 많거나 직업성 폐질환의 가능성을 가 지고 있는 예에서는 더욱 주의를 요한다 ${ }^{30 ~ 32)}$.

\section{결 론}

저자는 각종 폐질환의 호흡기능에 관한 연구의 일환으 로 1985년 1월부터 1986년 8월까지 중증 폐결핵으로 진 단되어 부산대학교 의과대학 부속병원 결핵격리병동에 
입원치료 하였던 80 예(남자 46 예 및 여자 34 예) 외 대조 군으로 비흡연 건강성인 120 예 (남녀 각각 60 예) 를 대상 으로 하여 폐환기 기능검사, 폐확산능 검사 및 동맥혈 가 스분석을 시행하여 다음과 같은 결과를 얻었다.

1) 중증 폐결핵 환자의 노력성호기곡선검사에서 구한 각 계측치 즉 $\mathrm{FCV}, \mathrm{FEV}_{1}, \mathrm{FEV}_{1} \%, \mathrm{FEF} 25 \sim 75 \%$, 및 $\mathrm{FEF} 75 \sim 85 \%$ 는 정상대조군에 비하여 유의한 감소를 보였다 $(\mathrm{p}<0.05)$.

2) 중증 폐결핵 환자의 최대호기류량-용적곡선검사에 서 구한 각 계측치 즉 $\mathrm{PEFR}, \dot{\mathrm{V}} \max 25 \%, \dot{\mathrm{V}} \max 50$ $\%$ 및 $\dot{\mathrm{V}} \max 75 \%$ 는 정상대조군에 비하여 유의한 감소 를 보였다 $(\mathrm{p}<0.05)$.

3) 중증 폐결핵 환자의 노력성 호기 폐활량 곡선 및 최 대호기류량-용적곡선검사에서 구한 각 계측치는 유병기 간이 길어짐에 따라 점차 감소하는 경향을 보였다.

4) 중증 폐결핵 환자의 최대호기량-용적곡선검사에서 구한 각 계측치의 용량교정치는 유병기간이 길어짐에 따 라 감소하는 경향을 보였다.

5) 중증 폐결핵 환자의 폐확산능 및 폐용적에 대한 폐 확산능은 정상대조군에 비하여 유의한 감소를 보였다 $(\mathrm{p}<0.05)$.

6) 중증 폐결핵 환자에서 폐확산능은 FVC 및 $\mathrm{FEV} 1$ 과 각각 서로 유의한 순상관관계를 보였다 $(\mathrm{r}=0.578$, $\mathrm{P}<0.001$ 및 $\mathrm{r}=0.457, \mathrm{P}<0.05)$.

7) 동맥혈 가스분석에서 중증 폐결핵 환자의 $\mathrm{PaO}_{2}$ 및 $\mathrm{SaO}_{2}$ 은 정상대조군에 비하여 유의하게 감소되어 있었다 $(\mathrm{p}<0.001$ 및 $\mathrm{p}<0.01)$.

\section{REFERENCES}

1) Stead WW: Pathogenesis of the sporadic case of tuberculosis. N Engl J Med 277:1008, 1967

2) Stead WW: Pathogenesis of a first episode of chronic pulmonary tuberculosis in man. Am Rev Respir Dis 95:729, 1967

3) Stead WW: Tuberculosis among elderly person: An outbreak in nursing home. Ann Int Med 94:606, 1981

4) Welty C, Burstin S, Muspratt S, Tager IB: Epidemiology of tuberculosis infection in a chronic care population. Am Rev Respir Dis 132:133, 1985

5) 대한결핵협회 : 제 4 차 전국 결핵실태조사보고. 결핵 연구원 연구 논문집, 제 2 집, p 406, 대한결핵협회, 서 울. 제 63 차 결핵학회 추계학술대회 초록집, 1986
6) 김건열 : 폐결핵에서의 폐기능 이상. 결핵, 대한결핵협 회, 대한결핵학회, p 117, 상문상사, 서울. 1984

7) Goldmann: 100IV computerized pulmonary function laboratory operators manual. 1981

8) Crofton J, Douglas A: Respiratory diseases and tuberculosis. 3rd ed, p 265, Blackwell scientific publications, Oxford, 1981

9) Bates DV, Macklem PT, Christe RV: Respiratory function in disease. 2nd ed, p 410, WB Saunder, Philadelphia, 1971

10) Birath G: Forms of chronic cardiopulmonary insufficiency in pulmonary tuberculosis and their diagnosis. Acta Tuber Scand 47:32 (suppl), 1959

11) Wolinsky E: Tuberculosis. In textbook of pulmonary diseases edited by Baum GL and Wolinsky E, 3rd ed, p 507, Little Brown and Company, Boston, 1983

12) Richman SI: Meanings of impairment and disability. Chest $78: 367,1980$

13) 김재원, 정혜영, 김광성, 이중연, 오중근, 유희성, 오 상백 : 폐결핵 환자의 일반적 폐환기 기능. 결핵 및 호 홉기질환 20:5, 1973

14) Bromberg PA, Robin ED: Abnormalities of lung function in tuberculosis. Adv Tuberc Res 12:1, 1961

15) Lancaster JF, Tomashefski JF: Tuberculosis-a cause of emphysema. Am Rev Respir Dis 87:67, 1962

16) Green M, Mead J, Turner JM: Variability of maximum expiratory flow-volume curves. J Appl Physiol $37: 67,1974$

17) Jayamanne DS, Epstein H, Goldring RM: The influence of lung volume on expiratory flow rates in diffuse interstital lung disease. Am J Med Scien 275: 329, 1978

18) Crapo RO, Morris AH: Standard single breath normal values for carbon monoxide diffusing capacity. Am Rev Respir Dis 123:185, 1981

19) Williams MH, Seriff NS, Akyol T, Yoo OH: The diffusing capacity of the lung in acute pulmonary tuberculosis. Am Rev Respir Dis 84:814, 1961

20) Dietiker F, Lester W, Gottlieb R, Burrows P: Single Breath pulmonary diffusing capacity measurements in patients with pulmonary tuberculosis. Am Rev Respir Dis 84:807, 1961

21) Tager I, Speizer FE: Role of infection in chronic bronchitis. N Engl J Med $292: 563,1975$

22) Rokaw SN, Detels R, Coulson AH, Sayre JW, Tashkin DP, Allwright SS, Massey FJ: The UCLA population studies of chronic obstructive respira- 
tory disease Chest 78:252, 1980

23) Birath G, Caro J, Malmberg R, Simnsson BG: Airways obstruction in pulmoriary tuberculosis. Scand J Resp Dis 47:27, 1966

24) Malberg R, Simnsson B, Berglund F: Airways obstruction and uneven gas distribution in the lung. Thorax 18:168, 1963

25) Soederholm B: The hemodynamics of the lesser circulation in pulmonary tuberculosis. Effect of exercise, temporary pulmonary artery occlusion and operation. Scand J Clin Lab Invest 9:26 (suppl), 1957

26) Uggla G: Pulmonary hypertension in tuberculosis of the lung. Acta Tuberc Scand 41:1 (suppl), 1957

27) Weg JG: Tuberculosis. In pulmonary medicine edit-
Lippincott Company, Philadelphia, 1982

ed by Guenter CA and Welch MH 2nd ed, p 390, JB

28) Neumann RD, Sostman HD, Gottschalk A: Current status of ventilation perfusion imaging. Seminars Nuc Med 10:198, 1980

29) Lopez-Majano V, Wagner H, Tow DE, Chernick V: Radioisotope scanning of the lung in pulmonary tuberculosis. J Am Med Ass 194:1053, 1965

30) Franklin W, Lowell FC: Smoking and emphysema. Ann Int Med 24:379, 1961

31) Blue ML, Janoff A: Possible mechanisms of emphysema in cigarette smokers. Am Rev Respir Dis 122:577, 1980

32) Beck GL, Doyle CA, Schachter EN: Smoking and lung function. Am Rev Respir Dis 123:149, 1981 